\title{
LAS RESTRICCIONES VERTICALES COMO ELEMENTO DE PROTECCIÓN AL MERCADO INTERNO EN LA UNIÓN EUROPEA Y SU APLICACIÓN EN COLOMBIA ${ }^{1}$
}

The Vertical Restrictions as an Element of Protection to the Internal Market in the European Union and its Application in Colombia

\author{
Diego Enrique Cruz Mahecha ${ }^{2}$ \\ Oscar Manuel Ariza Orozco ${ }^{3}$
}

Fecha de Recepción: 18 de noviembre de 2015

Fecha de Aceptación: 2 de diciembre de 2015

SUMARIO: 1. Las restricciones verticales en la Unión Europea; 2. Restricciones verticales en el sistema colombiano; 3. Conclusión; 4. Referencias bibliográficas.

\footnotetext{
${ }^{1}$ El presente artículo es derivado de la investigación titulada Las restricciones verticales como elemento de protección al mercado interno en la Unión Europea y su aplicación en Colombia. Esta investigación es el resultado del Doctorado en Derecho adelantado por los autores, quienes en este artículo fungen como investigadores principales.

${ }^{2}$ Abogado Universidad Católica. Especialista en derecho Administrativo, en Derecho Tributario y Aduanero, Magister en Derecho Constitucional y candidato a doctor en Derecho, Universidad Sergio Arboleda. Docente en programas de especialización y maestría en las áreas que integran el derecho público, Universidad de la Sabana.

${ }^{3}$ Abogado de la Universidad Militar Nueva Granada, UMNG, Bogotá. Especialista en Gestión Pública e Instituciones Administrativas, Universidad de los Andes, Bogotá. Magíster en Estudios Políticos, Pontificia Universidad Javeriana, Bogotá. Profesor Asociado del Área de Derecho Público, Facultad de Derecho y Ciencias Políticas Universidad de Cartagena. Coinvestigador del grupo Filosofía del Derecho, Derecho internacional y Problemas Jurídicos Contemporáneos de la Facultad de Derecho y Ciencias Políticas de la Universidad de Cartagena. Correo: oscarariza2001@yahoo.com
} 


\section{COMO SE CITA ESTE ARTÍCULO (APA 6)}

Cruz Mahecha, Diego Enrique; Ariza Orozco, Oscar Manuel (2016). Las restricciones verticales como elemento de protección al mercado interno en la Unión Europea y su aplicación en Colombia. Revista Jurídica Mario Alario D’Filippo, VIII (15), pág 128-141.

\section{RESUMEN}

Una aproximación al sistema jurídico y a la estructura social y comercial propia de la Unión Europea despierta en unos neófitos en tales materias una ingente curiosidad intelectual, proyectada no solo en ahondar en la naturaleza de sus instituciones, sino en la forma en que estas podrían aplicarse en el entorno colombiano. Se estudiarán, entonces, estas instituciones como medios de regulación de la actividad económica, las cuales, al adoptar acciones prohibitivas y/o sancionatorias, propugnan por la conservación y proyección del mercado interno y buscan oportunidades, en cuanto a las relaciones con el mercado internacional.

\section{PALABRAS CLAVES}

Restricciones verticales, actuaciones prohibitivas, regulación, Unión Europea.

\section{ABSTRACT}

An approach to the legal system and social and commercial structure of the European Union awakens in some neophytes in such matters an enormous intellectual curiosity, designed not only to delve into the nature of the institutions of the European Union, but in the exploration of how these could be applied in the Colombian environment. These institutions will be studied, then, as means of regulation of economic activity, which by adopting prohibitory and / or punitive actions, advocate the conservation and projection of the domestic market and seek relevance in terms of the relationship with the international market.

\section{KEYWORDS}

Vertical restrictions, prohibitive actions, regulation, European Union. 


\section{LAS RESTRICCIONES VERTICALES EN LA UNIÓN EUROPEA}

Al reparar sobre el tema escogido, la protección al mercado interno, se observó que frente al mismo existe una amplia regulación en la Unión Europea. Para la presente investigación se partirá del contenido de la comunicación del 10 de mayo de 20104, relativa a las restricciones verticales, la cual tiene una naturaleza compilatoria. En esta se esbozó la definición, el objeto y la razón de ser de tales restricciones, denotando los efectos que pueden predicarse de tal figura ${ }^{5}$ En el siguiente párrafo repasaremos algunos aspectos de pronunciamiento.

Se considera en tal documento que la génesis del tema tratado lo constituye lo dispuesto en el artículo 101, apartado 1, del Tratado de Funcionamiento de la Unión Europea (TFUE) ${ }^{6}$ En este se prohíbe todo acuerdo que pueda afectar la actividad comercial en los países que conforman la Unión Europea, así como cualquier actividad que impida, restrinja o falsee las actividades que se involucran en la competencia ${ }^{7}$ A reglón seguido se indicó que son permitidos los acuerdos que creen suficientes beneficios como para superar los efectos contrarios a la competencia, que, por tal razón, estarán exentos de cualquier prohibición , conforme al mismo artículo 101 - apartado 3. Estas últimas conductas se entienden como actividades permitidas dentro del mercado de la Unión Europea.

Antes de dar un paso más hacia la valoración de las restricciones verticales en la Unión Europea y la posible pertinencia que tendría su aplicación en el medio colombiano, se estima pertinente definir con claridad qué se entiende por restricción vertical. Para ello es necesario acudir al concepto más común sobre el particular, el cual sirvió de base a la Unión Europea para erigir el pronunciamiento en referencia, la definición que aporta la OECD (organización para la cooperación y el desarrollo económico), "Las restricciones verticales se refieren a cierto tipo de prácticas efectuadas por fabricantes o productores relacionadas con la reventa de su producto", pero a esta noción básica,

\footnotetext{
4 “las directrices y comunicaciones de la comisión, como complemento y guía a la autoevaluación que tiene que realizar las partes de sus acuerdos restrictivos, son instrumentos suficientes y más eficaces que la técnica de las exenciones por categorías para garantizar los principios de eficacia y uniformidad en la aplicación del art.101 del tratado" Véase: Baches Opi, S. (2014) Distribución y Derecho de la Competencia, el reglamento de la Unión Europea sobre Restricciones Verticales. Madrid: Marcial Pons, Ediciones Jurídicas y Sociales, p. 36.

${ }^{5}$ Para más información sobre los resultados de esta comisión véase: Unión Europea. Comunicación del 10 de mayo de la Comisión Europea (2010). Recuperado de: http://eur-lex.europa.eu/legal-content/ES/TXT/?uri=URISERV\%3Acc0007

${ }^{6}$ Afirma Baches Opi (2014):

[...] tanto la comisión como los tribunales comunitarios interpreten el articulo 101.1 como una norma encaminada a preservar una "competencia razonable" o "workable competition", en la terminología anglosajona. Con esta expresión se quiere significar que la aplicación e interpretación de este precepto debe realizarse esencialmente a la luz de estos objetivos, incluyendo de modo preferente el de la integración económica, pues se parte de la premisa de que la creación y el mantenimiento de un mercado interior en su factor la eficaz asignación de los recursos de toda la unión europea." (98)

${ }^{7}$ Contnuando con Baches Opi (2014). En la página 40 explica:

[...] El análisis de la práctica de la comisión europea y de la jurisprudencia de los tribunales comunitarios demuestra que existe un acuerdo en el sentido del artículo 101.1 del tratado, incluso cuando la conducta anticompetitiva, que sirve de causa al mismo, no se adopta en interés o no beneficia a los distribuidores; también cuando en contrato permite a una de las partes modificar unilateralmente las estipulaciones de un acuerdo, o incluso cuando una de las partes depende de la otra parte y su consentimiento ha sido prestado con intimidación.( subrayado nuestro)
} 
se suma la expresada por la Fiscalía Nacional Económica de Chile (2011), quien en su texto denominado Las Restricciones Verticales, repasando los conceptos de la Comisión Europea, señaló que:

Las restricciones verticales son acuerdos o prácticas concertadas celebradas entre dos o más empresas. Cada empresa opera, a efectos del acuerdo, en una fase económica diferente, en lo que se refiere a la entrega, a la compra de bienes destinados a la reventa o la transformación y a la comercialización de servicios. El acuerdo regula las condiciones en las que las partes pueden comprar, vender o revender determinados bienes o servicios. ${ }^{8}$

Esta remembranza nos permite observar a las restricciones verticales como una práctica que se profesa de quienes intervienen como actuantes oferentes en un mercado. Pueden partir de una iniciativa privada, o como se presentará en este escrito, pueden fungir como herramienta de la organización estatal o supranacional, orientada a conservar la normalidad del mercado, la protección a la industria nacional y a los consumidores en general.

Continuemos repasando lo dicho por la Unión Europea (2010) en el documento relativo a las restricciones verticales al que ya hemos hecho referencia. Se establece en tal directriz que "Los acuerdos verticales son acuerdos para la compraventa de bienes o servicios suscritos entre empresas que operan en planos distintos de la cadena de producción o distribución" Lo anterior permite inferir la existencia de múltiples procedimientos y actos sobre los que pueden desarrollarse los acuerdos verticales. Las medidas que toma la Unión Europea ${ }^{9}$ se proyectan, así, sobre una serie de prácticas específicas-que no fungen como criterios taxativos y condicionados fijos- a partir de las cuales se determina el alcance de la medida de protección o de la restricción y las posibles repercusiones que ambos casos pueden traer al mercado, la competencia y la economía en general.

Las restricciones verticales vistas como herramientas de regulación propia de la administración estatal se conciben en el seno de la Unión Europea como prácticas que no deben tener, únicamente, efectos negativos, sino que por el contrario también puede tener efectos positivos. Esta visión bipartita permite que las medidas de regulación que se erijan con fundamento en las denominadas restricciones verticales se puedan considerar como actuaciones prohibitivas, reglamentarias o de incentivo, que constituyen la herramienta predilecta de la autoridad nacional o supranacional. En estas situaciones la respectiva autoridad actúa como reguladora del mercado y encargada del afianzamiento de las sanas prácticas de competencia y de la conservación y crecimiento de la economía.

\footnotetext{
${ }_{8}^{8}$ Para revisar ambos conceptos, véase Irrazábal, F. (2011) Restricciones Verticales. FISCALÍA NACIONAL ECONÓMICA. Recuperado de: http://www.fne.gob.cl/wp-content/uploads/2011/11/PPT-Restricciones-Verticales.pdf

9 "Los acuerdos verticales que simplemente determinan el precio y la cantidad de una transacción de compraventa específica normalmente no restringen la competencia. No obstante, puede producirse una restricción de competencia si el acuerdo contiene restricciones al proveedor o al comprador" Cita recuperada de Comunicación relativa a las restricciones verticales de mayo 10 de 2010 , publicado en Eur-lex:,consultada en: http://eur-lex.europa.eu/legal-content/ES/TXT/?uri=URISERV\%3Acc0007 el 1 agosto de 2015.
} 
Así las cosas, es viable establecer que la Unión Europea, en su condición de autoridad administrativa, ha logrado mediar con relativo éxito las prácticas propias de los distintos sectores productivos de la economía, a través de las restricciones verticales, con los intereses superiores que se encuentran inmersos en el concepto competencia de mercado, y que representan a su vez, los intereses que asisten a la plataforma económica de las distintas organizaciones jurídico-políticas que la integran.

En la comunicación relativa a las restricciones verticales que nos ha servido de guía para la elaboración de estas líneas se consignó, a manera de introducción, un razonamiento del cual es posible apreciar la función bipartita, prohibición-incentivo, que se le ha brindado a las restricciones verticales en la Unión Europea. En tal escrito se señaló que "el hecho de que un acuerdo vertical restrinja realmente la competencia y que, en ese caso, los beneficios superen los efectos contrarios que se causen a la competencia, a menudo dependerá de la estructura del mercado, y así su pertinencia" (Unión Europea, 2010) Para determinar, por tanto, si la medida de restricción vertical debe instituirse prohibiendo o incentivando una práctica se debe previamente valorar por parte de la autoridad respectiva las condiciones propias del mercado, la participación de productores y/o comercializadores y el impacto que puede generar la medida que se adopte en la sociedad. ${ }^{10}$

Por lo anterior en el seno de la Unión Europea se ha adoptado un reglamento que se identifica de la siguiente forma: $E U-N^{\circ} 330 / 2010$, Reglamento de Exención por Categorías $(R E C)^{11}$, el cual en términos de la misma Unión Europea, "es el instrumento que proporciona un puerto seguro a la mayoría de acuerdos verticales". Este claro objetivo que se ha trazado la Unión Europea se logra mediante el establecimiento de una serie de exenciones por categorías ${ }^{12}$, en virtud de la cual desarrolla la aplicación de la prohibición que se plasmó en el artículo 101, apartado 1, del TFUE. ${ }^{13}$

\footnotetext{
10 "las normas de defensa de la competencia no persiguen un objetivo único. Por el contrario, son varios los objetivos que simultáneamente o separadamente, las autoridades antitrust pueden perseguir mediante la aplicación de la política y la normativa de la competencia" Idea que se corresponde con el objeto que se le otorga a las restricciones verticales, según la obra escrita por Baches Opi, S. (2014) Distribución y Derecho de la Competencia, el reglamento de la Unión Europea sobre Restricciones Verticales. Madrid: Marcial Pons, Ediciones Jurídicas y Sociales, p. 97.

${ }^{11}$ Disponible en: http://eur-lex.europa.eu/legal-content/ES/TXT/?uri=celex:32010R0330

${ }^{12}$ El concepto categoría corresponde a acciones de diversa naturaleza que regulan distintos aspectos de la actividad comercial. Véase: Baches Opi, S. (2014) Distribución y Derecho de la Competencia, el reglamento de la Unión Europea sobre Restricciones Verticales. Madrid: Marcial Pons, Ediciones Jurídicas y Sociales, en especial las sentencias referidas en tal obra "considerando 2 de la sentencia TPI. decisión de la comisión del 10 d enero de 1996, asunto IV/34.279/f3- ADALAT (96/478/ec), DOUEl 201,1996 y stjce de 6 de enero de 2004, bundesverband der arzeimittel-importeure ev et altri c. comisión, asuntos acumulados c-2/01p y c-3701 p, rep.2004, pi-23"

${ }^{13}$ Tratado de funcionamiento de la unión europea, articulo 101, apartado 1:

Serán incompatibles con el mercado interior y quedarán prohibidos todos los acuerdos entre empresas, las decisiones de asociaciones de empresas y las prácticas concertadas que puedan afectar al comercio entre los Estados miembros y que tengan por objeto o efecto impedir, restringir o falsear el juego de la competencia dentro del mercado interior y, en particular, los que consistan en:

a. fijar directa o indirectamente los precios de compra o de venta u otras condiciones de transacción;

b. limitar o controlar la producción, el mercado, el desarrollo técnico o las inversiones;

c. repartirse los mercados o las fuentes de abastecimiento;

d. aplicar a terceros contratantes condiciones desiguales para prestaciones equivalentes, que ocasionen a éstos una desventaja competitiva;

e. subordinar la celebración de contratos a la aceptación, por los otros contratantes, de prestaciones suplementarias que, por su naturaleza o según los usos mercantiles, no guarden relación alguna con el objeto de dichos contratos.

Tratado disponible en: http://noticias.juridicas.com/base_datos/Admin/ttce.p3t7.html
} 
El entorno sobre el que se desarrolla este objetivo, como bien lo señala el texto contentivo de las mencionadas directrices, no es otro que indicar que cuando los acuerdos verticales que se erijan no estén cubiertos por el REC, es decir aquellas medidas que se relacionen con operaciones en donde la cuota de mercado que compete a un proveedor o comprador determinado supera el $30 \%$, del porcentaje total del mercado, es dable que tal límite no se entienda per se, como causal de ilegalidad (Unión Europea, 2010). A reglón seguido se indica que tal "umbral solo sirve para distinguir los acuerdos que se benefician de una presunción de legalidad de los que requieren un examen individual. Las Directrices ayudan a las empresas a llevar a cabo dicho examen". Lo anterior nos sirve para denotar uno de los criterios de aplicación y funcionamiento que en la práctica se profesa de las restricciones verticales, más cuando se pretende hacer uso de ellas. Esta temática se corresponde con los problemas que se ha abordado en este escrito, pero que no constituye el núcleo de la presentación que se ha venido realizando. Como bien se ha expresado, nuestro objetivo no es otro que esbozar los aspectos y prácticas más frecuentes y destacadas que, en cuanto a las restricciones verticales, se han dado en la Unión Europea.

La comunicación compilatoria que nos ha servido de guía indica que su naturaleza es fungir como norma general, "para la evaluación de restricciones verticales y proporcionan criterios para la evaluación de los tipos de restricciones verticales más comunes: marca única (obligaciones de no competir), distribución exclusiva, asignación de cliente exclusivo, distribución selectiva, franquicia, suministro exclusivo, pagos de acceso inicial, acuerdos de gestión por categoría, vinculación y restricciones de los precios de reventa" (Unión Europea, 2010) Del proceso de identificación de las prácticas de mercado sobre las que se pueden aplicar las restricciones verticales quedo claro que el detonante para establecer este tipo de medidas son los efectos anticompetitivos de algunas prácticas que, necesariamente, han de afectar el normal funcionamiento del mercado y de paso contribuyen al quebrantamiento del estándar de la competencia. Claro este objetivo es pertinente señalar que aunque no son taxativas las razones para la adopción de restricciones verticales en la Unión Europea, con ellas se pretendió evitar la ocurrencia de las siguientes conductas:

- Exclusión contraria a la competencia de otros proveedores o compradores.

- Relajación de la competencia y facilitación de la colusión entre el proveedor y sus competidores.

- Relajación de la competencia entre el proveedor y sus competidores y facilitación de la colusión.

- Creación de obstáculos a la integración de mercados (Unión Europea, 2010).

Por otra parte, en cuanto a los efectos positivos que en la Unión Europea se predican de las restricciones verticales se encuentra el fomento de la competencia, abordando aspectos que van más allá de temas como los precios y las medidas para mejorar la calidad 
de los bienes o servicios a ofrecer en el mercado. Al respecto obsérvese que cuando la restricción es positiva se predica que "su eficiencia es mayor cuando las restricciones verticales son de duración limitada, [...] pues contribuyen a la introducción de nuevos productos complejos, protegen las inversiones destinadas a determinadas relaciones o facilitan la transferencia de conocimientos"14 (Unión Europea, 2010). La temporalidad como característica que puede asistir a las restricciones verticales, como bien ocurre en la Unión Europea, es una herramienta fundamental para incentivar actividades económicas en el mercado interno y colaborar al posicionamiento de una industria o sector de la economía, aspecto clave en un estructura como la colombiana, en donde la industria nacional mono-productiva, es una realidad permanente.

Hemos tenido la oportunidad de valorar el concepto de restricciones verticales, así como los principales efectos que a estas se le han atribuido en la Unión Europea. Resaltando que esta temática posee aspectos técnicos y procedimentales específicos, a los cuales no se hará referencia en este escrito, a continuación se procede a señalar las prácticas que constituyen restricciones verticales más utilizadas en la U.E.

En Comunicación calendada el 13 de octubre de 2000 la Comisión Europea, al exponer las primeras directrices atinentes a las restricciones verticales, estableció los actos que constituyen las denominadas restricciones verticales más comunes, en el ámbito europeo. Allí se referencian prácticas como la denominada Marca Única, Distribución Exclusiva, Exclusividad de Clientela, Distribución Selectiva, Franquicia, Suministro Exclusivo, Venta Vinculada, Precios de Venta Recomendados o Máximos ${ }^{15}$ (Union Europea, 2000), medidas

\footnotetext{
${ }^{14}$ Véase "El nuevo tratamiento de las restricciones verticales en el derecho comunitario de la competencia" (1999) escrito por Carlos pascal, y disponible en http://www.revistasice.info/cachepdf/BICE_2626_13-20__64929B2E467A13D286634AD1863CF895.pdf Consultada el 1 agosto de 2015.

${ }^{15}$ A continuación, y siguiendo las explicaciones ofrecidas en Unión Europea. Comunicación del 13 de octubre de la Comisión Europea (2000). Recuperado de: http://eur-lex.europa.eu/legal content/ES/TXT/?uri=celex:32000Y1013(01) se explicarán cada una de estas prácticas:

- Marca única: cuando una cláusula contractual obliga o incita al comprador a cubrir prácticamente todas sus necesidades en un mercado determinado, abasteciéndose en un único proveedor, se habla de marca única. Esto no significa que el comprador deba abastecerse directamente en el proveedor, pero significa que no comprará, no revenderá o no integrará en sus productos bienes o servicios competidores. Desde el punto de vista de la competencia, las cláusulas de este tipo corren el riesgo de cerrar el acceso al mercado de los proveedores competidores o potenciales, de facilitar la colusión entre proveedores en caso de utilización acumulativa y, cuando el comprador es un minorista que vende a los consumidores finales, de debilitar la competencia intermarca dentro del punto de venta.

- Distribución Exclusiva: en el marco de un acuerdo de distribución exclusiva, el proveedor acepta no vender su producción más que a un único distribuidor para su reventa en un territorio determinado. Al mismo tiempo, el distribuidor ve a menudo limitadas sus ventas activas hacia otros territorios exclusivos. Desde el punto de vista de la competencia, este sistema corre el riesgo sobre todo de debilitar la competencia intramarca y de compartimentar el mercado, de modo que de ello pudiera resultar una discriminación por los precios. Cuando la mayoría o la totalidad de los proveedores aplican la distribución exclusiva, eso puede facilitar la colusión, tanto a su nivel como al de los distribuidores.

- Exclusividad de clientela: en el marco de un acuerdo de exclusividad de clientela, el proveedor acepta no vender sus productos más que a un único distribuidor con fines de reventa a una determinada categoría de clientes. Al mismo tiempo, el distribuidor está a menudo limitado en sus ventas activas a otras clientelas asignadas. Desde el punto de vista de la competencia, este sistema corre el riesgo sobre todo de debilitar la competencia intramarca y de compartimentar el mercado, de modo que podría dar lugar a discriminación por los precios. Cuando la mayoría o la totalidad de los proveedores aplican la exclusividad de clientela, ello puede facilitar la colusión, tanto a su nivel como al de los distribuidores.

- Distribución selectiva: tal como ocurre con los acuerdos de distribución exclusiva, los acuerdos de distribución selectiva limitan, por una parte, el número de distribuidores autorizados y, por otra, sus posibilidades de reventa. En contra de lo que ocurre con la
} 
que al día de hoy han evolucionado hasta el punto de que el debate sobre la materia ya no tiene como núcleo el tipo de actuación sobre las que se materializan las restricciones verticales, sino la injerencia de estas medidas, sobre el mercado, en la oferta y la demanda que en esta se integra.

Esta temática es abordada por Sergio Baches Opi, en su obra Distribución y Derecho de la Competencia - El Reglamento de la Unión Europea sobre Restricciones Verticales (2014). En tal escrito se presentan algunas de esas medidas con las que se busca, a través de la aplicación de criterios propios de tales restricciones, generar efectos en la oferta y la demanda, en el mercado. Baches Opi indica: "La comisión que aludía con carácter general al poder de compra de la demanda como uno de los factores pertinentes para la evaluación de un acuerdo vertical con arreglo al artículo 101.1, constató que este poder se deriva de la posición en el mercado del comprador" (2014). El "poder de compra" funge como punto de partida de la injerencia de la autoridad administrativa en el mercado a través de las denominadas restricciones verticales. En los últimos años se ha acompañado la función de regulación del mercado que le asiste a la administración con criterios que permiten la adopción de medidas de intervención directa, dirigidas hacia la protección de las condiciones normales del mercado y de los intereses del consumidor. También se considera como factor propio de las políticas basadas en la utilización de las restricciones verticales, a fin de fomentar la estabilidad del mercado, el uso de aspectos que corresponden a la denominada gestión por categorías (category management), "por

distribución exclusiva, la limitación del número de minoristas autorizados no depende del número de territorios, sino de criterios de selección vinculados en primer lugar a la naturaleza del producto. Otra diferencia consiste en el hecho de que la restricción en materia de reventa no afecta a las ventas activas efectuadas fuera de un territorio, sino a todas las ventas realizadas con distribuidores no autorizados, ya que entonces los minoristas autorizados y los consumidores finales son los únicos compradores potenciales. La distribución selectiva casi siempre se utiliza para distribuir productos finales de marca. Desde el punto de vista de la competencia, este tipo de distribución corre el riesgo de debilitar la competencia intramarca y, sobre todo si hay efecto acumulativo, de eliminar uno o más tipos de distribuidores y de facilitar la colusión entre proveedores o compradores.

- Franquicia: los acuerdos de franquicia incluyen una licencia de derechos de propiedad intelectual relativos a marcas o signos distintivos o a unos conocimientos técnicos para la utilización y la distribución de bienes y servicios. Además de una licencia de derechos de propiedad intelectual, el franquiciador proporciona normalmente al franquiciado, durante el período de aplicación del acuerdo, una asistencia comercial o técnica. La licencia y esta asistencia forman parte integrante del método comercial franquiciado. Por regla general, el franquiciador percibe del franquiciado un canon por la utilización del método comercial en cuestión. La franquicia puede permitir al franquiciador establecer, con unas inversiones limitadas, una red uniforme para la distribución de sus productos. Desde el punto de vista de la competencia, la concesión del método comercial y los acuerdos de franquicia contienen en general una combinación de restricciones verticales referentes a los productos distribuidos, en particular la distribución selectiva y/o la exclusividad de marca y/o la distribución exclusiva o alguna forma suavizada de estas restricciones.

- Suministro Exclusivo: el suministro exclusivo implica que el proveedor no puede vender un producto final determinado más que a un único comprador dentro de la Comunidad. En el caso de los bienes o servicios intermedios, el suministro exclusivo significa que dentro de la Comunidad no hay más que un único comprador o más que un único comprador para un uso determinado. En el caso de los bienes o servicios intermedios, el suministro exclusivo a menudo se asimila a un suministro industrial. Desde el punto de vista de la competencia, el suministro exclusivo corre el riesgo sobre todo de dar lugar a la expulsión de otros compradores.

- Venta Vinculada: hay venta vinculada cuando un proveedor supedita la venta de un producto a la compra, a ese proveedor o a alguien designado por él, de otro producto distinto. El primer producto se llama el bien o servicio "vinculante" y el segundo, el producto "vinculado". Cuando las ventas vinculadas no se justifican objetivamente por la naturaleza de los productos o por el uso comercial, pueden constituir un abuso de posición dominante. Desde el punto de vista de la competencia, este tipo de acuerdo, destinado a supeditar la venta de un producto a la compra de otro producto distinto, puede violar las normas de la competencia.

- Precios de Venta Recomendados o Máximos: la práctica consiste en recomendar un precio de venta a un minorista o en exigir a un minorista que respete un precio de venta máximo. Desde el punto de vista de la competencia, los precios máximos o recomendados corren el riesgo sobre todo de funcionar como punto de convergencia para los minoristas y de ser seguidos por la mayoría, o incluso por la totalidad, de los mismos. Además, corren el riesgo de facilitar la colusión entre proveedores. 
esta se entiende como el método de gestión comercial al que recurren los minoristas para maximizar las ventas de los productos que pertenecen a una determinada categoría y que consiste en contratar los servicios de un proveedor líder en la categoría para que organice la comercialización de dicha categoría" (Baches Opi, 2014) o los pagos de posicionamiento (por espacio lineal o promociones):

Se entiende por esta las cantidades que abonan los fabricantes o proveedores a los minoristas en el marco de una relación vertical al principio de un periodo para obtener acceso a su red de distribución y remunerar ciertos servicios prestados por estos últimos a los proveedores, en la práctica, estos pagos tienen como finalidad principal remunerar al distribuidor por el espacio o parcela lineal que reservan a los productos de un determinado fabricante (Baches Opi, 2014).

Esta breve referencia realizada permitió entender algunas de las prácticas que dentro de la Unión Europea han servido en la estabilización de su plataforma económica, bajo criterios de sostenibilidad y una proyección hacia el crecimiento. Criterios que nos brindan los elementos suficientes para valorar lo que acontece en nuestro medio en cuanto al manejo que se le ha brindado a las restricciones verticales. El resultado de tal ejercicio académico nos permitirá concluir si es conveniente en Colombia la utilización de estas restricciones verticales, desde las perspectivas de utilización tanto positivas como negativas, no concibiéndolas únicamente como medio de control, sino como herramienta de fomento y posicionamiento de actividades económicas y de mercado.

\section{RESTRICCIONES VERTICALES EN EL SISTEMA COLOMBIANO}

Como se enunció en los apartes iniciales, en el medio Colombiano también existen las denominadas restricciones verticales. Estas se proyectan primariamente desde la perspectiva de los sujetos que integran el mercado (en su mayoría de naturaleza privada), en donde se les concibe como medidas de fomento e incluso protección al mercado y a la competencia justa.

En cuanto a lo que corresponde a la administración pública, el uso de estas medidas de restricción se concibe preferentemente más como medidas regulatorias de naturaleza sancionatoria. Para observar esa realidad se acudirá a los planteamientos que sobre esta materia se plasman en el artículo titulado "Restricciones verticales en la política de competencia colombiana, parámetros análisis de casos", publicado en la revista de Derecho Privado y Comunicaciones de la Universidad de los Andes (Ruiz, 2014). En la parte introductoria del artículo se indica, respecto a las restricciones verticales, que

En Colombia, la libre competencia es un derecho de carácter constitucional y, en este sentido, las políticas que la protegen se dirigen a evitar que esta libertad se vea restringida. Esta legislación contiene normas sobre prácticas restrictivas de la competencia, esto es, acuerdos anticompetitivos o carteles; actos anticompetitivos; situaciones de abuso de posición dominante, y obligaciones relacionadas con el control previo de integraciones 
empresariales (Superintendencia de Industria y Comercio [SIC], Guía sobre aplicación de normas). A su vez, esta legislación declara a la SIC la autoridad única en materia de protección de la competencia (5).

Un primer elemento que se denota a simple vista de la anterior cita, en lo que respecta al papel que compete a las restricciones verticales, es el de fungir como medio para proteger la sana competencia y las condiciones del mercado. Es importante indicar que en Colombia los procesos mencionados competen a esta sola institución, la cual depende enteramente del poder ejecutivo. Su accionar se caracteriza por que opera principalmente de oficio, es decir, en sus actuaciones prima el criterio institucional, por lo que solo intervine cuando lo estima pertinente y sobre los aspectos que estime relevantes de acuerdo a su percepción del mercado.

En este artículo se realiza una remembranza de la normatividad que en Colombia ha regulado los asuntos relativos a la competencia y dentro de tal reglamentación lo atinente a las restricciones verticales. Repasemos la evolución normativa en la materia. En primer lugar encontramos la ley 155 de $1959^{16}$, con ella se buscaba proteger la competencia, pero sus efectos se diluyeron por la complejidad del asunto tratado y la constante evolución del mercado. Posteriormente como consecuencia de la apertura económica que se dio en Colombia en la década de 1990, se expidió el decreto 2153 de 1992, el cual aumentó la cobertura de la norma de competencia (Ruiz, 2014, 9) Como consecuencia de la evolución económica del país y del mercado, el gobierno definió en "el Plan Nacional de Desarrollo 2006-2010, la necesidad de un cambio normativo, cuya resultante fue la expedición de la ley 1309 de 2009.Esta ley dispuso que la SIC fuera la autoridad con potestad para aplicar la legislación sobre competencia. En la actualidad, tanto la Ley 155/1959 y el Decreto2153/1992, como la Ley 1340/2009, están vigentes" (íbid).

En el texto seleccionado para abordar este tema, se enuncia que en materia de restricciones verticales:

el artículo 1 de la Ley 155/1959 establece la prohibición de acuerdos o convenios que directa o indirectamente tengan por objeto limitar la producción, abastecimiento, distribución o consumo de materias primas, productos, mercancías o servicios nacionales o extranjeros y, en general, toda clase de prácticas, procedimientos o sistemas con tendencia a limitar la libre competencia y a mantener o determinar precios no equitativos. (9)

Continúa el artículo indicando que esta prohibición se desarrolla y amplía su espectro con lo dispuesto en el Decreto 2153 de $1992^{17}$, en el cual:

\footnotetext{
16 “En Colombia la Ley 155 de competencia fue aprobada en 1959. Para ese entonces, la ley se basaba en la coyuntura de la época y, por tanto, sus lineamientos partían de la Constitución de 1886, en especial de su artículo 32. Sin embargo, la legislación que acompañó a esta ley no fue suficiente para su implementación eficaz, difuminándose así su objetivo principal: la protección de la competencia" (Ruiz, 2014,9)

${ }^{17}$ ARTICULO 47. ACUERDOS CONTRARIOS A LA LIBRE COMPETENCIA.

Para el cumplimiento de las funciones a que se refiere el artículo 44 del presente Decreto se consideran contrarios a la libre competencia, entre otros, los siguientes acuerdos:

1. Los que tengan por objeto o tengan como efecto la fijación directa o indirecta de precios.

2. Los que tengan por objeto o tengan como efecto determinar condiciones de venta o comercialización discriminatoria para con terceros.
} 
(...) estipuló que los acuerdos pueden ser contrarios a la libre competencia, tanto por su objeto como por sus efectos. Este decreto, además, estableció una definición que incluye una lista taxativa de acuerdos o carteles, estipulando que por estos se entenderá "todo contrato, convenio, concertación, práctica concertada o conscientemente paralela entre dos o más empresas". Asimismo, en este decreto se incluyó una lista no exhaustiva de acuerdos que se consideran contrarios a la libre competencia. (9)

\section{Los elementos presentados correspondientes a las restricciones verticales en Colombia nos muestran cómo en este ordenamiento la institucionalización y desarrollo de tales}

3. Los que tengan por objeto o tengan como efecto la repartición de mercados entre productores entre productores o entre distribuidores. 4. Los que tengan por objeto o tengan como efecto la asignación de cuotas de producción o de suministro.

5. Los que tengan por objeto o tengan como efecto la asignación, repartición o limitación de fuentes de abastecimiento de insumos productivos. 6. Los que tengan por objeto o tengan como efecto la limitación a los desarrollos técnicos.

7. Los que tengan por objeto o tengan como efecto subordinar el suministro de un producto a aceptación de obligaciones adicionales que por su naturaleza no constituían el objeto del negocio, sin perjuicio de lo establecido en otras disposiciones.

8. Los que tengan por objeto o tengan como efecto abstenerse de producir un bien o servicio o afectar sus niveles de producción.

9. Los que tengan por objeto la colusión en las licitaciones o concursos o los que tengan como efecto la distribución de adjudicaciones de contratos, distribución de concursos o fijación de términos de las propuestas.

10. Los que tengan por objeto o tengan como efecto impedir a terceros el acceso a los mercados o a los canales de comercialización. Véase http://www.secretariasenado.gov.co/senado/basedoc/decreto_2153_1992.html Consultada el 10 de agosto del 2015

ARTICULO 48. ACTOS CONTRARIOS A LA LIBRE COMPETENCIA. Para el cumplimiento de las funciones a que se refiere el artículo 44 del presente Decreto, se consideran contrarios a la libre competencia los siguientes actos:

1. Infringir las normas sobre publicidad contenidas en el estatuto de protección al consumidor.

2. Influenciar a una empresa para que incremente los precios de sus productos o servicios o para desista de su intención de rebajar los precios.

3. Negarse a vender o prestar servicios a una empresa o discriminar en contra de la misma cuando ello pueda entenderse como una retaliación a su política de precios.

ARTICULO 49. EXCEPCIONES. Para el cumplimiento de las funciones a que se refiere el artículo del presente Decreto, no se tendrán como contrarias a la libre competencia las siguientes conductas:

1. Las que tengan por objeto la cooperación en investigaciones y desarrollo de nueva tecnología.

2. Los acuerdos sobre cumplimientos de normas, estándares y medidas no adoptadas como obligatorias por el organismo competente cuando no limiten la entrada de competidores al mercado.

3. Los que se refieran a procedimientos, métodos, sistemas y formas de utilización de facilidades comunes.

ARTICULO 50. ABUSO DE POSICION DOMINANTE. Para el cumplimiento de las funciones a que refiere el artículo 44 del presente Decreto, se tendrá en cuenta que, cuando exista posición dominante, constituyen abuso de la misma las siguientes conductas:

1. La disminución de precios por debajo de los costos cuando tengan por objeto eliminar uno varios competidores o prevenir la entrada o expansión de éstos.

2. La aplicación de condiciones discriminatorias para operaciones equivalentes, que coloquen a un consumidor o proveedor en situación desventajosa frente a otro consumidor o proveedor de condiciones análogas.

3. Los que tengan por objeto o tengan como efecto subordinar el suministro de un producto a la aceptación de obligaciones adicionales, que por su naturaleza no constituían el objeto del negocio, sin perjuicio de lo establecido por otras disposiciones.

4. La venta a un comprador en condiciones diferentes de las que se ofrecen a otro comprador cuando sea con la intención de disminuir o eliminar la competencia en el mercado.

5. Vender o prestar servicios en alguna parte del territorio colombiano a un precio diferente de aquel al que se ofrece en otra parte del territorio colombiano, cuando la intención o el efecto de la práctica sea disminuir o eliminar la competencia en esa parte del país y el precio no corresponda a la estructura de costos de la transacción.

6. Obstruir o impedir a terceros, el acceso a los mercados o a los canales de comercialización.

ARTICULO 51. INTEGRACION DE EMPRESAS. El nuevo texto es el siguiente: La autoridad nacional de competencia podrá no objetar una integración empresarial si los interesados demuestran dentro del proceso respectivo, con estudios fundamentados en metodologías de reconocido valor técnico que los efectos benéficos de la operación para los consumidores exceden el posible impacto negativo sobre la competencia y que tales efectos no pueden alcanzarse por otros medios.

de competencia podrá expedir las instrucciones que especifiquen los elementos que tendrá en cuenta para el análisis y la valoración de los estudios presentados por los interesados.

ARTICULO 52. PROCEDIMIENTO. Para determinar si existe una infracción a las normas de promoción a la competencia y prácticas comerciales restrictivas a que se refiere este Decreto, la Superintendencia de Industria y Comercio deberá iniciar actuación de oficio o por su solicitud de un tercero y adelantar una averiguación preliminar, cuyo resultado determinará la necesidad de realizar una investigación. Cuando se ordenó abrir una investigación, se notificará personalmente al investigado para que solicite o aporte las pruebas que pretenda hacer valer. Durante la investigación se practicarán las pruebas solicitadas y las que el funcionario competente considere procedentes. 
restricciones se ha proyectado de una forma eminentemente regulatoria y primaria ${ }^{18} \mathrm{El}$ estado colombiano busca mantener las condiciones de mercado que considera deben imperar, reprochando y excluyendo la realización de una serie de conductas previamente tipificadas, que se entienden atentatorias contra la competencia al interior del mercado nacional. Por esto no sería errado indicar que esta figura en Colombia se entiende más como una medida de control de naturaleza sancionatoria que como un medio de fomento de la industria y el mercado. Esta característica que impera en el manejo de las restricciones verticales en nuestro ordenamiento, no es óbice, sin embargo, para que ellas puedan proyectarse hacia otros efectos que se pueden generar en beneficio del crecimiento del mercado y el posicionamiento de una industria o actividad, que se considere vital para la economía nacional.

\section{CONCLUSIÓN}

La presentación de los aspectos básicos de la regulación vertical en la Unión Europea, así como lo propio en lo que respecta al ámbito Colombiano, nos permite hacer un ejercicio de comparación, aunque algo simple (no por la naturaleza misma del ejercicio, si no por lo general de los conceptos presentados), pero pertinente. De esta conclusión es posible plantear dos premisas fundantes en este tema.

La primera se relaciona con el objeto de las restricciones verticales en el ordenamiento y la segunda, que es una consecuencia lógica de la primera, es la importancia que para la economía nacional puede traer dar un giro en la utilización de las restricciones verticales. En el entorno Colombiano se podría dar a la política de las restricciones verticales un tinte que permita entenderlos más que como un instrumento de control, sino de herramienta para incentivar el crecimiento del mercado y la industria nacional.

Ahondemos un poco en la primera premisa enunciada en el párrafo anterior. En la Unión Europea se conciben las restricciones verticales como una acción con efectos negativos y positivos que se materializan en acciones permisivas y restrictivas. Esta visión tradicional es acompañada con un uso diferente de tales facultades: servir de instrumento para el posicionamiento de un sector económico en el cual el Estado tiene especial interés, o para que la competencia se profese sana e igualitaria en sus condiciones. Desde el punto de vista de la práctica se reconoce la diversidad del mercado interno y las condiciones propias de cada país, a fin de mantener la industria nacional y comunitaria, así como los benéficos económicos que ella genera en materias como la generación de empleo, la sanidad tributaria y el progreso social.

\footnotetext{
${ }^{18} \mathrm{El}$ análisis de casos de restricciones verticales en Colombia no encaja exactamente en alguno de los modelos de análisis que se han establecido en otras legislaciones, tales como los criterios de ilegalidad per se y la "regla de la razón" (rule of reason). La discusión en cuanto a qué análisis se debe aplicar a los casos de restricciones verticales no ha arrojado resultados tan claros, puesto que la legislación colombiana sobre competencia y, en especial, el régimen de responsabilidad administrativa no se adaptan claramente a ninguna de las dos tendencias internacionales (OCDE) (Ruiz, 2014, 11)
} 
Esos efectos positivos que se pudieron observar en la aproximación que se efectuó a la temática de las restricciones verticales en la Unión Europea pueden ser predicables en el ámbito colombiano si se acompañara el uso de las restricciones verticales como facultades de regulación y vigilancia, (funciones restrictivas y sancionatorias), con la faceta que a estas las convierte en medio para incentivar y acrecentar las condiciones del mercado, con todas las consecuencias positivas que ello implica.

\section{REFERENCIAS BIBLIOGRÁFICAS}

\section{Libros}

Baches Opi, S. (2014) Distribución y Derecho de la Competencia, el reglamento de la Unión Europea sobre Restricciones Verticales. Madrid: Marcial Pons, Ediciones Jurídicas y Sociales.

Isla, A. Z. (2006). Las restricciones verticales a la libre competencia. Madrid: S.L. CIVITAS EDICIONES.

\section{Revistas}

Estudios de la libre competencia, consumidor y regulación (2013). Compilación. Revista del centro de libre competencia de la Facultad de Derecho de la Pontificia Universidad Católica. (1) Libro Tecnia.

Miranda Londoño, A. (1998). Los acuerdos anticompetitivos de repartición de mercados. Contexto, (3).

Pascual Pons, C. (1999). El nuevo tratamiento de las Restricciones Verticales en el Derecho Comunitario de la Competencia. Boletín ICE Económico: Información Comercial Española, (2626), 13-20.

Ruiz, L. (2014) Restricciones Verticales en la Política de la Competencia ColombianaParámetros Análisis de Caso. Revista de Derecho Privado, Comunicaciones y Nuevas Tecnologías. Universidad de los Andes, (11), 4-31.

\section{Páginas web}

Decreto 2153 de 1992. Recuperado de: http://www.secretariasenado.gov.co/senado/ basedoc/decreto_2153_1992.html

Irrazábal, F. (2011) Restricciones Verticales. FISCALÍA NACIONAL ECONÓMICA. Recuperado de: http://www.fne.gob.cl/wp-content/uploads/2011/11/PPT-RestriccionesVerticales.pdf 
UniónEuropea.(2000).Comunicación del13 deoctubre dela ComisiónEuropea. Recuperado de: http://eur-lex.europa.eu/legal-content/ES/TXT/?uri=celex:32000Y1013(01)

- (2010) Comunicación del 10 de mayo de la Comisión Europea. Recuperado de: http://eur-lex.europa.eu/legal-content/ES/TXT/?uri=URISERV\%3Acc0007

_. (2010) REGLAMENTO (UE) N 330/2010 DE LA COMISIÓN. Recuperado de: http:// eur-lex.europa.eu/legal-content/ES/TXT/?uri=celex:32010R0330

Tratado de funcionamiento de la Unión Europea, articulo 101, apartado 1. Recuperado de: http://noticias.juridicas.com/base_datos/Admin/ttce.p3t7.html 